University of Navarra

\title{
THE ORGANIZATIONAL TENSION BETWEEN STATIC AND DYNAMIC EFFICIENCY
}

\author{
Pankaj Ghemawat ${ }^{\star}$ \\ Joan E. Ricart* \\ RESEARCH PAPER № 255 \\ October, 1993 \\ * Professors of General Management, IESE
}

Research Division

IESE

University of Navarra

Av. Pearson, 21

08034 Barcelona - Spain 


\title{
THE ORGANIZATIONAL TENSION BETWEEN STATIC AND DYNAMIC EFFICIENCY
}

\begin{abstract}
Efficiency has been defined in at least two different ways: in terms of the refinement of existing products, processes or capabilities (static efficiency) and as the development of new ones (dynamic efficiency). This paper analyzes the organizational trade-off between these two forms of efficiency. It shows that there is a tendency towards extremes, and that the irreversibility of efficiency orientations tends to tip the balance to be struck between static and dynamic efficiency toward the latter. The paper also advances hypotheses about industry, business and corporate factors that mediate between the choice of a particular efficiency orientation and organizational performance.
\end{abstract}

We are grateful to Chris Argyris, Joseph Bower, Clayton Christensen, David Collis, Anita McGahan, Nitin Nohria, Gary Pisano, Richard Rosenbloom, Arthur Schleifer, Jr., Josep Valor, and David Yoffie and the editors for helpful comments on an earlier draft of this paper. This paper was prepared while Ricart was a Research Fellow at the Harvard Business School during the 1992-1993 academic year, when he was supported in part by the Secretary of State for Universities and Research at the Ministry of Education and Science in Madrid. Ghemawat's research was supported by the Division of Research at the Harvard Business School. 


\section{THE ORGANIZATIONAL TENSION BETWEEN STATIC AND DYNAMIC EFFICIENCY}

This paper builds on the growing literature on the firm as an informationprocessing entity. It focuses on a basic tension in processing information: using it to search for improvements within a framework of fixed beliefs about how the environment behaves and responds to organizational actions versus using it to reconsider the beliefs themselves. Implicit in this tension are two understandings of efficiency (or actually, efficiency-oriented search processes): static efficiency, which involves continuous search for improvements within a fixed set of initial conditions, and dynamic efficiency, which involves continuous reconsideration of initial conditions.

In this paper, we seek to advance the analysis of the trade-off between static and dynamic efficiency. Section 1 touches upon some related literature. Section 2 models the single-period allocation of a fixed information-processing resource between the imperatives of static and dynamic efficiency and relates the model's identification of a possible tendency toward extremes -toward an exclusive focus on either static or dynamic efficiency- to practical considerations. Section 3 analyzes a multi-period extension of the basic model and emphasizes that, in most circunstances, once a commitment is made to a particular efficiency orientation, this tends to tip optima toward dynamic efficiency relative to the single-period benchmark. Section 4 sketches some hypotheses about how the performance of an organization of a particular type may be affected by its industry environment and strategic choices. Section 5 concludes.

\section{Some related literature}

The distinction between static and dynamic efficiency has not passed unnoticed. We cite just a few prominent sightings here and apologize in advance to the authors of other important studies which are omitted. The distinction between static and dynamic efficiency is evident in Ashby's [1956] seminal work on systems analysis, which distinguishes between a single-loop system, rather like a thermostat, which adjusts to environmental changes in preprogrammed ways, and a more complicated double-loop system, in which the lower-level feedback loop can be reprogrammed by a second, higherlevel loop. In organization theory, Burns and Stalker [1961] crystallize similar considerations into two ideal organizational types, mechanistic and organic, that are suited to stable and changing environments respectively; and Argyris and Schon [1974] distinguish between single-loop and double-loop organizational learning in a way that evokes Ashby's loops and influences our definitions of the two types of efficiency. 
In technology and operations management, the distinction between static and dynamic efficiency is implicit in Abernathy's [1978] productivity dilemma: the idea that a productive unit cannot be both highly efficient (in a static sense) and support a high rate of innovation. In terms of strategic management, and from a more pedagogical perspective, it is worth noting that until quite recently an important linchpin of the strategy formulationimplementation sequence at the Harvard Business School was a note that emphasized the distinction between "Type A" organizations, developed for current efficiency and regularity, and "Type B" organizations, developed for innovation and flexibility (Heskett [1987]).

The distinction between static and dynamic efficiency has also been examined by economists, mostly under the heading of flexibility. We discuss their work in slightly more detail because of its connections to our own. Stigler [1939] and Hart [1942] initiated economic research in this area by analyzing the cost penalties incurred in adapting production technologies to changes in demand by adjusting output levels, an inverse measure of flexibility. Marschak and Nelson [1962] broadened the analysis to consider adaptation to all forms of environmental turbulence, not just to changes in demand. Jones and Ostroy [1984] apply option-theoretic concepts to analyze the value of flexibility. The two most interesting economic treatments for our purposes, however, are those of Klein [1984] and Carlsson [1989].

Klein [1984] begins by distinguishing between static and dynamic efficiency, defining the former as "fine-tuning whose objective is to make the best use of existing information" (p. 50). In other words, he defines static efficiency as the optimal combination of given inputs, subject to the constraints imposed by a fixed production function. Dynamic efficiency, in contrast, is defined as "changing the production function in profitable directions" (p. 46). Klein goes on to differentiate dynamic efficiency into two types of flexibility (p. 47). Type I flexibility is associated with anticipated uncertainty (or "risk" in the sense of Knight [1921]) and is "built into production processes so they can produce quite dissimilar existing products on the same production line... It is aimed at rapid short-term response to changes in market conditions by permitting very significant shifts in the composition of output without the usual penalties involved in closing down entire production lines." Type II flexibility, in contrast, is associated with unanticipated uncertainty ("true" Knightian uncertainty) and "is concerned with the ability to make good use of newly disclosed opportunities, be they opportunities for improving the production process or developing and producing new products".

Carlsson [1989] builds on Klein's work but comes up with a somewhat different scheme for classifying flexibility: into its operational, tactical and strategic aspects. Operational flexibility is associated with the short run and is defined as "built-in procedures which permit a high degree of variation in sequencing, scheduling, etc." (p. 47). Tactical flexibility is associated with the medium run and "is built into the technology, i.e., the organization and the production equipment, of the firm and enables it to deal e.g. with changes in the rate of production or in product mix over the course of the business cycle, as well as moderate changes in design." Finally, strategic flexibility is associated with the long run and "reflects how the firm positions itself with respect to a menu of choices for the future". Although Klein's and Carlsson's classification schemes are obviously related to each other, it should be noted that they have different bases: the type of uncertainty and the length of the time horizon, respectively.

We shall offer our own definitions of what we mean by orientations toward static and dynamic efficiency in the next section and in the context of a specific model. What needs to be explained here are the ways in which our definitions differ from Klein's and Carlsson's, 
and why. To focus on Klein's definitions, we regard his intermediate category, Type I flexibility, as basically a hybrid (or convex combination) of his two polar ones and reduce his three categories to two: static efficiency and dynamic efficiency (where our definition of dynamic efficiency corresponds most closely to his definition of Type II flexibility). Second, we are attracted to a basis of classification, learning, that is different from Klein's (type of uncertainty) and Carlsson's (time horizon) because it emphasizes the influence of organizational choices instead of largely exogenous environmental attributes.

The literature on organizational learning has a long and distinguished pedigree (e.g., March and Olsen [1976]). The most helpful part of it for present purposes is Argyris and Schon's [1974] distinction, referred to earlier, between single- and double-loop learning. Single-loop learning evokes Ashby's thermostat and involves the adaptation of actions in response to discrepancies between intentions and outcomes but within a given framework of beliefs. Double-loop learning, in contrast, also involves "going meta" on those beliefs by reconsidering them.

Single- and double-loop learning have affinities with our definitions of static and dynamic efficiency respectively. Once again, however, the correspondence is approximate rather than exact. Argyris and Schon [1974] appear to imply that double-loop learning is always superior to single-loop learning. We think that that proposition should be probed, not postulated. More specifically, we see a tension between the two feedback loops involved in double-loop learning: one takes initial conditions to be fixed while the other focuses on changes in initial conditions. The two loops differ in their temporal emphases, so that temporally distinct choices about what to do effectively alter the weights attached to them. Alternatively, information processing involves assigning relative weights to two distinct inferential processes, one concerning possible improvements within the current framework of beliefs and the other concerning the way those beliefs might usefully be revised in light of the data. The next section examines this weighting problem in the context of a simple one-period model.

\section{A one-period model}

The simple model presented in this section supplies a language for discussing static and dynamic efficiency and analyses the trade-off between the two. The analysis indicates the possibility of a tendency toward extremes: toward a focus on either static or dynamic efficiency. Practical considerations appear to increase the probability of such extreme possibilities.

\subsection{Assumptions}

Our model of organizational information processing assumes optimization and therefore abstracts away from the fact that organizations' information-processing capabilities are rarely the outcome of completely rational choice processes (e.g., March and Simon [1958], Cyert and March [1963]). The assumption of optimization helps focus attention on the pure incentives for learning. It also implies that the organization can be treated as operating on the efficiency frontier. Note that the trade-off between static and dynamic efficiency which we analyze need not apply to an organization that operates well within the efficiency frontier. 
The state of the world in period $t$ is represented as an unknown random variable called $\theta_{t}$. The state of the world changes from period 0 to period 1 according to the following process:

$$
\theta_{1}=\lambda \theta_{0}+(1-\lambda) \delta_{1}
$$

where $1 \in[0,1]$, with extreme values corresponding to a random environment ( $\lambda=0$ ) and a stable one $(\lambda=1)$. The initial state, $\theta_{0}(\equiv \theta)$, and the change factor, $\delta_{1}$, are assumed to be independent random variables drawn from a normal distribution with mean $\mu$ and variance $v$. These assumptions are made for the sake of simplicity and could, to some degree, be relaxed. For example, most of the results that follow would also hold for change processes that are martingales:

$$
\theta_{t}=\theta_{t-1}+\lambda \delta_{t}
$$

where $\lambda \in[0, \infty)$. Similarly, $\theta$ and $\delta_{1}$ can have different means and variances as long as they are independent of each other.

The information structure of the model comes next. We posit that the organization has a fixed resource, say attention, to be allocated between learning about the initial state $\theta$ and the change factor $\delta_{1}$. We assume that the organization allocates attention by choosing a variable $\mathrm{x} \in[0,1]$ and then observing noisy signals $\left(s_{1}, d_{1}\right)$ of $\left(\theta, \delta_{1}\right)$, with the variances of the signals depending on the choice of $\mathrm{x}$. To be more specific, we make the following assumptions:

$$
\begin{aligned}
& s_{1}=\theta+\varepsilon_{1}, \\
& d_{1}=\delta_{1}+\alpha_{1},
\end{aligned}
$$

where $\varepsilon_{1}$ and $\alpha_{1}$ are independently, identically and normally distributed with means and variances of, respectively, $\left(0, v_{\varepsilon}(x)\right)$ and $\left(0, v_{\alpha}(x)\right)$, and $v_{\varepsilon}(x)$ decreases with $\mathrm{x}$ and $v_{\alpha}(x)$ increases with $x$. The organization places an extreme emphasis on static efficiency if it chooses $x=1$ (so that most of its learning is about the initial state) and a similarly extreme emphasis on dynamic efficiency if it chooses $x=0$ (so that most of its learning is about the change factor). given by

The organization's objective function is kept simple. Its profits are assumed to be

$$
y_{1}=Y_{1}-\left(\theta_{1}-\hat{\theta}_{1}\right)^{2}
$$

where $\hat{\theta}_{1}$ is the organization's estimate of $\theta_{1}$ and $Y_{1}$ is a random variable such that $y_{1}$ is totally uninformative about the state of the world. This assumption, which can be relaxed to a degree, highlights the causal ambiguity of performance outcomes, although its principal purpose is to let us treat the signals, $s_{1}$ and $d_{1}$, as sufficient statistics. The organization's objective can then be boiled down to forming the best estimate of the state of the world in order to minimize the squared error term in equation (3). 
2.2. Analysis

Based on the preceding assumptions, the best estimate of the state of the world is $E\left[\theta_{1} \mid x, s_{1}, d_{1}\right]$ and the organization should choose $\mathrm{x}$ to minimize the following variance term:

$$
\operatorname{Var}\left[\theta_{1} \mid x, s 1, d_{1}\right]=\lambda^{2} v_{\theta}^{P}(x)+(1-\lambda)^{2} v_{\delta}^{P}(x)
$$

where $v_{\theta}^{P}(x)$ and $v_{\delta}^{P}(x)$ represent the posterior variances of $\theta$ and $\delta_{1}$ respectively.

Given our normal prior $N(\mu, v)$ and our normal signals, the posterior distribution of $\theta$ is normal with mean $\left(v s_{1}+v_{\varepsilon} \mu\right) /\left(v+v_{\varepsilon}\right)$ and variance $v_{\varepsilon} /\left(v+v_{\varepsilon}\right)$. Similar expressions can be derived for the posterior distribution of $\delta_{1}$ (Cyert and DeGroot [1987], p. 18.). Therefore, the posterior variances can be written as:

$$
\begin{aligned}
& v_{\theta}^{P}(x)=v v_{\varepsilon}(x) /\left[v+v_{\varepsilon}(x)\right] \\
& v_{\delta}^{P}(x)=v v_{\alpha}(x) /\left[v+v_{\alpha}(x)\right]
\end{aligned}
$$

and the corresponding derivatives are $v^{\prime} \varepsilon(x)\left[v /\left(v+v_{\varepsilon}(x)\right)\right]^{2}$ and $v^{\prime} \alpha(x)[v /(v+v \alpha(x))]^{2}$. Then the derivative of the variance term in equation (4) is equal to:

$$
\lambda^{2} v^{\prime} \varepsilon(x)\left[v /\left(v+v_{\varepsilon}(x)\right)\right]^{2}+(1-\lambda)^{2} v^{\prime} \alpha(x)[v /(v+v \alpha(x))]^{2}
$$

For compactness, define the terms

$$
\begin{aligned}
& z(x) \equiv-v^{\prime} \alpha(x)\left[v /\left(v+v_{\alpha}(x)\right)\right]^{2} /\left(v^{\prime} \varepsilon(x)\left[v /\left(v+v_{\varepsilon}(x)\right)\right]^{2}\right) \\
& =-\left[v^{\prime} \alpha(x) / v^{\prime} \varepsilon(x)\right]\left[\left(v+v_{\varepsilon}(x)\right) /\left(v+v_{\alpha}(x)\right)\right]^{2} \\
& F(\lambda) \equiv(\lambda /(1-\lambda))^{2}
\end{aligned}
$$

The first-order conditions for optimization can be written in these terms as:

(a) If $\mathrm{z}(\mathrm{x}) \geq \mathrm{F}(\lambda)$ for all $\mathrm{x} \in[0,1]$ then $\mathrm{x}^{*}=0$.

(b) If $\mathrm{z}(\mathrm{x}) \leq \mathrm{F}(\lambda)$ for all $\mathrm{x} \in[0,1]$ then $\mathrm{x}^{*}=1$.

(c) Otherwise, there is a $x^{*} \in(0,1)$ such that $z\left(x^{*}\right)=F(\lambda)$.

It is easy to show that $\mathrm{F}(\lambda)$ increases strictly, from 0 to $\infty$, as $\lambda$ increases from 0 to 1.Furthermore, provided that the variances as functions of $\mathrm{x}$ are sufficiently well behaved, $\mathrm{z}(\mathrm{x})$ is bounded in $[0,1]$ by $\underline{z}$ and $\bar{z}$, from below and above respectively, where $\bar{z}<\infty$ and $\underline{\mathrm{z}}$ $>0$. Given that $\mathrm{F}($.) is strictly increasing, we can solve $\mathrm{F}(\lambda)=\mathrm{z}$ for any $\mathrm{z}$, getting $\lambda=\sqrt{z} /(1+\sqrt{z})$. Therefore, we have our main result: 
(a) For all $\lambda \leq \sqrt{\underline{z}} /(1+\sqrt{z}), z(x) \geq F(\lambda)$ for all $\mathrm{x} \in[0,1]$ and $\mathrm{x}^{*}=0$.

(b) For all $\lambda \geq \sqrt{\bar{z}} /(1+\sqrt{\bar{z}}), z(x) \leq F(\lambda)$ for all $\mathrm{x} \in[0,1]$ and $\mathrm{x}^{*}=1$.

(c) For any other $\lambda$, there is an $x^{*} \in(0,1)$ such that $z\left(x^{*}\right)=F(\lambda)$.

This result is illustrated in Figure 1, which assumes that $\underline{z}=0.5$ and $\bar{z}=1.5$ (implying that the critical values of $\lambda$ are 0.41 and 0.55 ). There is a tendency to "locate" at extremes, i.e., to emphasize either static efficiency $\left(x^{*}=1\right)$ or dynamic efficiency $\left(x^{*}=0\right)$. These extreme locations are always present whatever the shape of $\mathrm{z}(\mathrm{x})$ because that function is always bounded.

Figure 1. The one-period case: An illustration

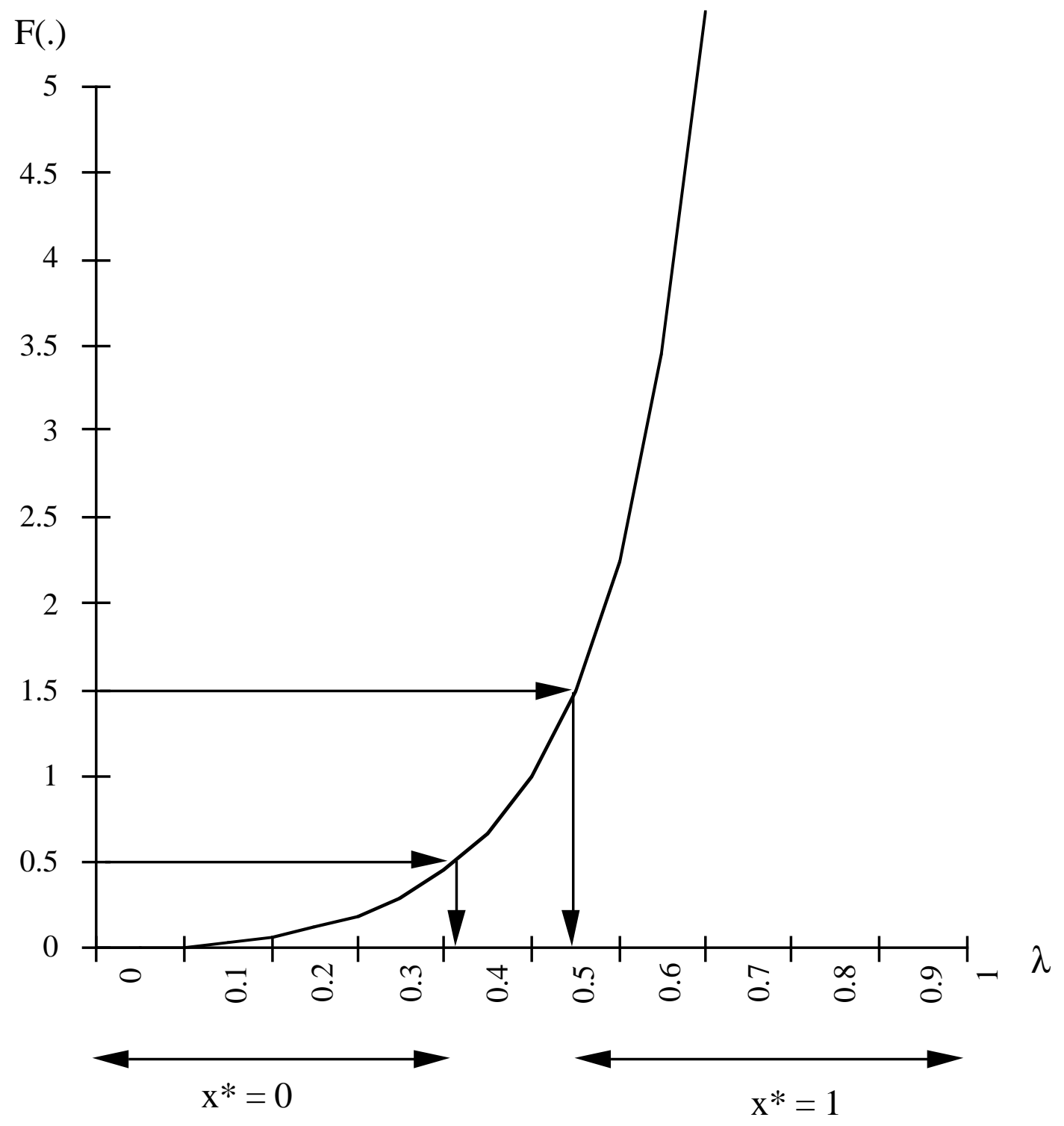


Restore parametric generality but consider a special case in which the prior distribution, $\mathrm{N}(\mu, v)$, is very diffuse, so that the firm can forget about the prior and use only the observations. The special case corresponds to the limit as the variance $v$ tends to $\infty$. The posterior distributions of $\theta$ and $\delta$ become, respectively, $N\left(s_{1}, v_{\varepsilon}(x)\right)$ and $N\left(d_{1}, v_{\alpha}(x)\right)$. As a result, $\mathrm{z}(\mathrm{x})$ reduces to the absolute value of the ratio of derivatives of the corresponding variances:

$$
z(x)=v^{\prime} \alpha(x) /\left(-v^{\prime} \varepsilon(x)\right) .
$$

When $\mathrm{z}(\mathrm{x})$ is constant for all $\mathrm{x} \in[0,1]$, both variances are linear functions of $\mathrm{x}$. Then there is a critical value, $\lambda^{*}=\sqrt{z} /(1+\sqrt{z})$, such that for any $\lambda<\lambda^{*}, \mathrm{x}^{*}=0$, and for any $\lambda>\lambda *, x^{*}=1 .^{1}$

\subsection{Discussion}

Knowing that there are always values of $\lambda$ low or high enough to force extreme solutions does not tell us anything about the actual incidence of such extremes. Practical considerations suggest, nonetheless, that these extreme possibilities should be taken seriously. This subsection discusses why.

The argument, baldly put, is that organizational arrangements that promote static efficiency may be inconsistent with arrangements that promote dynamic efficiency. The argument works at two levels. First, the pursuit of the two kinds of efficiency may not be consistent in its implications for individual organizational elements. Second, the requirement of consistency across individual organizational elements may reinforce the tension, forcing organizations to cluster into two relatively distinct archetypes (corresponding to $\mathrm{x}^{*}$ equal to 0 or to 1$)$.

An organizational element that illustrates these points particularly well is the structure of decision rights within an organization. A key concern in defining decision rights is the trade-off between the information or knowledge problem and the control problem (Jensen and Meckling [1992]). There are two broad alternatives. On the one hand, one might decentralize decisions in an attempt to harness idiosyncratic knowledge in different parts of the organization. This creates a control problem, however, because of the self-interest of the agents to whom decisions are delegated. Second, one might centralize decision-making in the belief that such idiosyncratic knowledge is not very relevant and that other specialized knowledge can be transmitted at low cost. Centralization solves the control problem at the expense of an information problem.

These decision structures have very different implications for the way organizations interact with their environment and therefore map differently onto our conceptions of static and dynamic efficiency. A control-driven organization with its top-down decision processes is likely to be better suited to the pursuit of static efficiency: after all, its managers prespecify the learning paths to be pursued. A knowledge-driven organization, in contrast, is likely to be comparatively well suited to the pursuit of dynamic efficiency because of its bottom-up emphasis on surfacing new opportunities: its managers may make some top-down plans but they will not make consistency with these plans a litmus test of newly disclosed opportunities. 
Similar arguments can be made regarding specific choices about other organizational elements (e.g., objective versus subjective performance incentives). Table 1 reproduces, as an extensive-form illustration, the elements listed in the Harvard Business School note cited earlier (Heskett [1987]).2 Although individual readers are likely to disagree with at least some of the characterizations in Table 1, its columnar structure suggests a second reason why organizations may, in terms of their efficiency orientations, cluster into two relatively distinct archetypes: in order to harness complementarities among choices concerning individual organizational elements. To the extent that it is hard or at least costly to "mix and match" across the two columns in Table 1 (or two columns that the reader might devise), that increases the amount of clustering to be expected at the extremes compared with what a simple row-by-row assessment might appear to indicate.

Table 1. Aligning elements of strategy

\begin{tabular}{cc} 
Summary of Type A Strategy \\
Resources & and Regularity \\
developed for Current Efficiency & $\begin{array}{c}\text { Summary of Type B Strategy } \\
\text { developed for Innovation and } \\
\text { Flexibility }\end{array}$ \\
\hline
\end{tabular}

Human Emphasis on quality of compliance and commitment

Emphasis on quality of originality and commitment

Financial Growth financed largely from ongoing business

Significant development investment requiring financial capacity

Technological Emphasis on incremental product and process improvements

Emphasis on the development of entirely new products and basic new technologies

Organization

\begin{tabular}{|c|c|c|}
\hline Structure & $\begin{array}{l}\text { Centralized/functional orientation } \\
\text { Clear vertical chain of authority for } \\
\text { decisions/communication } \\
\text { Sales and/or operations the dominant } \\
\text { functions }\end{array}$ & $\begin{array}{l}\text { Decentralized/product orientation } \\
\text { Network of influence and communication } \\
\text { Utilize projects and task forces } \\
\text { Marketing and/or R\&D the dominant } \\
\text { functions }\end{array}$ \\
\hline Controls & $\begin{array}{l}\text { Tight, detailed plans and budgets } \\
\text { Reviews at short intervals }\end{array}$ & $\begin{array}{l}\text { Loose planning around objectives } \\
\text { (management by objectives) }\end{array}$ \\
\hline Standards & $\begin{array}{l}\text { Specific individual or group targets } \\
\text { Compete with internal comparisons } \\
\text { "Stretch" goals defined in terms of sales or } \\
\text { production levels }\end{array}$ & $\begin{array}{l}\text { General targets } \\
\text { Compete with external comparisons } \\
\text { "Stretch" goals defined in terms of project } \\
\text { delivery dates }\end{array}$ \\
\hline Rewards & $\begin{array}{l}\text { Tie rewards to individual or group } \\
\text { performance } \\
\text { Promote for making plans } \\
\text { for failure }\end{array}$ & $\begin{array}{l}\text { Tie rewards to total business performance } \\
\text { Promote for innovative results } \\
\text { Reward risk-takers with "soft landing" }\end{array}$ \\
\hline $\begin{array}{l}\text { Policies/ } \\
\text { Processes }\end{array}$ & $\begin{array}{l}\text { Top-down decision process } \\
\text { Establish clear career tracks }\end{array}$ & $\begin{array}{l}\text { Bottom-up and top-down decision processes } \\
\text { Use a clear "maze" }\end{array}$ \\
\hline $\begin{array}{l}\text { Working } \\
\text { Environment }\end{array}$ & $\begin{array}{l}\text { Pride in military precision } \\
\text { Emphasis on making your numbers } \\
\text { in terms of costs, delivery and quality } \\
\text { Standard working hours and dress }\end{array}$ & $\begin{array}{l}\text { Pride in being first with bright ideas } \\
\text { Emphasis on creative teamwork } \\
\text { Working hours and dress to meet individual } \\
\text { preferences }\end{array}$ \\
\hline
\end{tabular}

Source: Excerpted from Heskett [1987]. 
While these arguments are informal, the mechanism they invoke can be illustrated by modifying the basic model presented earlier in this section to include complexity costs, costs that are higher for intermediate values of $\mathrm{x}$ than for extreme ones. Such complexity costs generalize the idea that it is strictly infeasible to combine organizational elements in particular ways: they imply that "mixing and matching" may be feasible but costly. We aggregate the various sources of complexity costs into the differentiable function $\mathrm{c}(\mathrm{x})$, and assume that the function is minimized at $\mathrm{x}=0$ and $\mathrm{x}=1$ and is single-peaked in between. In the presence of such costs, the organization's optimization problem becomes one of minimizing the following term:

$$
\operatorname{Var}\left[\theta_{1} \mid x, s_{1}, d_{1}\right]+c(x)=\lambda^{2} v_{\theta}^{P}(x)+(1-\lambda)^{2} v_{\delta}^{P}(x)+c(x) .
$$

The derivative with respect to $\mathrm{x}$ can be written as

$$
\lambda^{2} v^{\prime} \varepsilon(x)\left[v /\left(v+v_{\varepsilon}(x)\right)\right]^{2}+(1-\lambda)^{2} v^{\prime} \alpha(x)\left[v /\left(v+v_{\alpha}(x)\right)\right]^{2}+c^{\prime}(x) .
$$

Comparison of expressions (6) and (10) suggests that since $c^{\prime}(x)>0$ for small values of $\mathrm{x}$, complexity costs will expand the domain of $\lambda$ over which $\mathrm{x}^{*}$ should be set to 0 . Similarly, since $c^{\prime}(\mathrm{x})<0$ for large values of $\mathrm{x}$ (close to 1 ), they also expand the domain of $\lambda$ over which $\mathrm{x}$ should be set to 1 .

To conclude this section, we have highlighted the probability of extreme possibilities because of a sense that such nonconvexities are characteristic of strategy. ${ }^{3}$ The idea of making trade-offs at the margin -in this case, between specialization in an initial state of the world and the flexibility to adapt to changes in the initial state- is not very new. The idea that deserves additional emphasis is that organizations may need to do more than make marginal trade-offs: nonconvexities may nudge them to choose between distinct organizational archetypes.

\section{A multi-period model}

An obvious way to extend a single-period decision model is to generalize it to $\mathrm{T}$ periods, where $\mathrm{T}$ is a positive integer. In analyzing the implications of extra periods, two polar situations can be distinguished: situations in which the choice of $\mathrm{x}$ can be changed at no cost from period to period, and those in which it is fixed over the entire time horizon. Both polar situations will be analyzed in this section. Both imply more attention to dynamic efficiency than does the single-period benchmark, but for different reasons.

\subsection{Assumptions}

We maintain most of the assumptions of Section 2.1; the exceptions are made explicit here. The change process is now defined over T periods, as are its ingredients:

$$
\theta_{t}=\lambda \theta_{t-1}+(1-\lambda) \delta_{t}=\lambda^{t} \theta+(1-\lambda) \sum_{i} \lambda^{i} \delta_{t-i}\left(\sum_{i} \text { from i }=0 \text { to } \mathrm{t}-1\right)
$$


There are two additional differences. The first is that the organization's priors about the state of the world and the change factors are now assumed to be very diffuse. This means that the relevant variances $(v)$ equal $\infty$ and implies that the organization will rely solely on the information contained in the signals that it observes (as opposed to its prior beliefs). The assumption of very diffuse priors highlights the uncertainties that shroud choices about how to organize. It also spares us the complexities of fully Bayesian bookkeeping, without, we believe, affecting the tenor of our results.

The second difference or, to be more precise, qualification concerns the choice of $\mathrm{x}$. Given optimization, the choice of $x$ could be modeled in only one obvious way in the singleperiod version of our model. But with multiple periods, there are several modeling possibilities. The next subsection focuses its analysis, as mentioned above, on two extreme possibilities: situations in which $\mathrm{x}$ can be changed in each period and those in which it is fixed for $\mathrm{T}$ periods. An additional restriction is imposed at the latter extreme by our assumption that a commitment to a particular value of $\mathrm{x}$ for the rest of the time horizon must be made in the first period. The possibility of delaying the commitment in order to secure improved information is, unfortunately, ruled out as a result.

\subsection{Analysis}

We begin with the simpler of the two extreme possibilities, the situation in which the choice of $\mathrm{x}$ can be changed from period to period. It is easy to use the sort of analysis developed in the previous section to show that the period-by-period optimization of $\mathrm{x}$ involves comparison of $z\left(x_{t}\right)$, the absolute value of the ratio of the derivatives of the two variances as in equation (8), with the following term:

$$
F_{t}(\lambda)=(1+\lambda) \lambda^{2 t} /\left[\left(1-\lambda^{2 t}\right)(1-\lambda) t\right]
$$

It is also easy to show that $F_{t}(\lambda)$ decreases as $\mathrm{t}$, which indexes periods, increases and, for any finite $t$, increases from 0 to $\infty$ as $\lambda$ increases from 0 to 1 . By implication, as time passes, the optimal choice of $\mathrm{x}$ or location on the efficiency frontier $\left(\mathrm{x}^{*}\right)$ shifts toward dynamic efficiency (toward 0 ).

The more complicated extreme possibility is that $\mathrm{x}$ is chosen in period 1 and fixed at that level for the remaining (T-1) periods. The problem then becomes one of choosing $\mathrm{x}$ to minimize the following variance term:

$\sum_{t} \operatorname{Var}\left[\theta_{t} \mid x, s_{1}, d_{1}, \mathrm{~K}, S_{t}, d_{t}\right]=\sum_{t}\left[\lambda^{2 t} v_{\varepsilon}(x) / t+(1-\lambda)\left(1-\lambda^{2 t}\right) v_{\alpha}(x) /(1+\lambda)\right]\left(\sum_{t}\right.$ from $\mathrm{t}=1$ to $\left.\mathrm{T}\right)$.

The first-order conditions center on the derivative

$$
\sum_{t}\left[\lambda^{2 t} v^{\prime} \varepsilon(x) / t+(1-\lambda)\left(1-\lambda^{2 t}\right) v^{\prime} \alpha(x) /(1+\lambda)\right]
$$

and imply that the existence of interior as opposed to corner solutions for the value of $\mathrm{x}$ will depend on the relation between $z(x)$ and $F^{T}(\lambda)$, where 


$$
\begin{aligned}
& z(x) \equiv-v^{\prime} \alpha(x) / v^{\prime} \varepsilon(x), \\
& F^{T}(\lambda) \equiv(1+\lambda) \sum_{t}\left(\lambda^{2 t} / t\right) /\left[\left(T-\sum_{t} \lambda^{2 t}\right)(1-\lambda)\right] .
\end{aligned}
$$

Then the first-order conditions can be written as in the case of $\mathrm{T}=1$ :

(a) If $z(x) \geq F^{T}(\lambda)$ for all $\mathrm{x} \in[0,1]$ then $\mathrm{x}^{*}=0$.

(b) If $z(x) \leq F^{T}(\lambda)$ for all $\mathrm{x} \in[0,1]$ then $\mathrm{x}^{*}=1$.

(c) Otherwise, there is an $x^{*} \in(0,1)$ such that $z\left(x^{*}\right)=F^{T}(\lambda)$.

It is easy to show that $F^{T}(\lambda)$ increases from 0 to $\infty$ as $\lambda$ increases from 0 to 1 . Since $\mathrm{z}(\mathrm{x})$ is the same function as before, the results are analogous to the $\mathrm{T}=1$ case. What is of distinctive interest is how $F^{T}(\lambda)$ changes in T. It turns out that

$$
F^{T}(\lambda)-F^{T-1}(\lambda)<0,
$$

for all $\lambda \in[0,1]$ and any $\mathrm{T}$. Furthermore, as $\mathrm{T}$ goes to $\infty, F^{T}(\lambda)$ collapses to a discontinuous function which is zero for all $\lambda \in[0,1)$ and infinite for $\lambda=1$.

Figure 2 graphs $F^{T}(\lambda)$ for different values of $\mathrm{T}$ with the same parameters $(\underline{\mathrm{z}}=0.5$ and $\bar{z}=1.5)$ that were used in Figure 1 . The critical values of $\lambda$ move to the right as $\mathrm{T}$ increases. The impact of the multi-period extension is, therefore, to favor dynamic efficiency at the expense of static efficiency, but the interval for which $\mathrm{x}$ equals 1 does not vanish for any finite T. The tendency to "locate" at either extreme, i.e., to become oriented toward either static or dynamic efficiency, is still valid for any $\mathrm{T}$. In the special case when $\mathrm{z}(\mathrm{x})$ is constant for all $\mathrm{x} \in[0,1]$, both variances are linear functions of $\mathrm{x}$ and there is a critical value $\lambda^{T}$ for each $F^{T}(\lambda)$ such that for any $\lambda<\lambda^{T}, x^{T}=0$, and for any $\lambda>\lambda^{T}, x^{T}=1$. Furthermore, $\lambda^{T}$ increases in $\mathrm{T}$ and approaches 1 as $\mathrm{T}$ goes to $\infty$. 
Figure 2. The multi-period case: An illustration

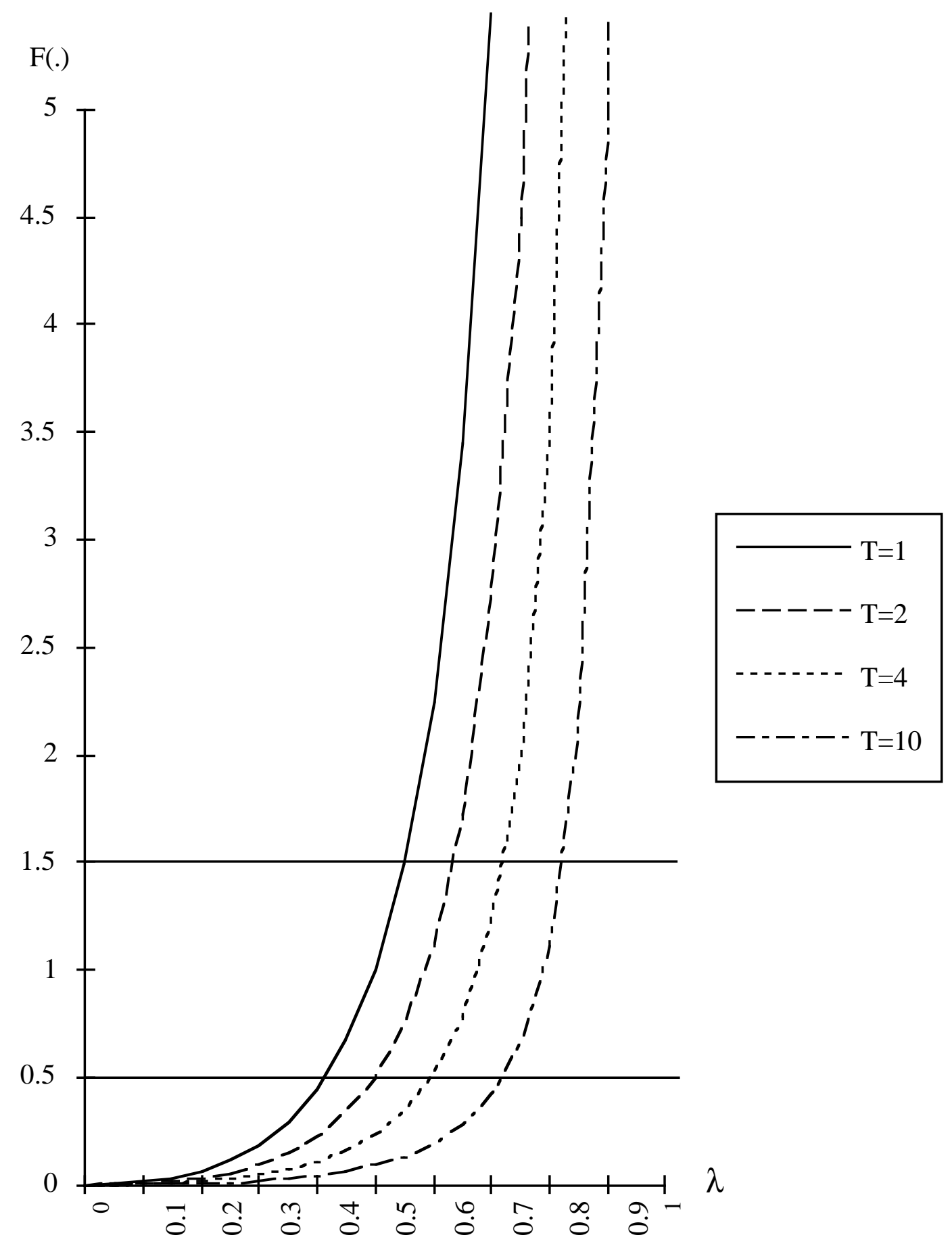




\subsection{Discussion}

The predictions that attention to dynamic efficiency ought to be enhanced by increases in $\mathrm{t}$ or $\mathrm{T}$ are not entirely intuitive: the former, for instance, is at odds with the idea that organizations place progressively more emphasis on static efficiency as time passes (e.g., Abernathy and Utterback [1978]). The predictions therefore deserve further discussion.

The case in which the choice of $\mathrm{x}$ can be changed from period to period is relatively simple to discuss as well as analyze. Consider what happens to the choice of a strategy oriented toward static efficiency $(\mathrm{x}=1)$ in such a situation. As time passes (t increases), much is learned about the initial state of the world, but the actual state of the world also tends to drift away from the estimated initial state. Within the framework of our model, the only optimizing response is to place more emphasis on dynamic efficiency as time passes. It would be useful to develop a more general model in which it is also possible to "refocus" by setting the clock back to $t=0$ : to reset the initial state without changing the organization's location on the (static versus dynamic) efficiency frontier. If refocusing is not too costly, that should increase the intertemporal viability of static efficiency relative to the model analyzed in the previous subsection.

The more complicated and, we believe, more important case concerns the situation in which $\mathrm{x}$ is constrained to the same value in all $\mathrm{T}$ periods. With $\mathrm{x}$ fixed, increases in $\mathrm{T}$ increase the implied degree of emphasis on dynamic efficiency. It is helpful, in this context, to interpret $\mathrm{T}$ as the organizational lag in implementing a new efficiency orientation (relocating to a rather different point on the efficiency frontier) rather than as a time horizon. The question then becomes why such lags should be assumed: why the choice of an efficiency orientation should involve significant commitment or irreversibility (Ghemawat [1991]).

The most obvious answer is that that is what the empirical evidence appears to indicate. Organizational arrangements usually do not change much each day, month or even year, and radical changes usually involve several organizational elements instead of being made piecemeal, element by element (e.g., Miller and Friesen [1984]). Radical organizational changes, such as changes in efficiency orientation, therefore tend to be relatively rare events separated by long intervals of time.

For a deeper answer, however, one must look at causal mechanisms rather than behavior. From an information-processing perspective, perhaps the most salient reason for the sluggishness of change between the two efficiency orientations is the one suggested by Arrow ([1974], p. 41). He focuses on the costs sunk into processing information in particular ways:

\footnotetext{
"Once the investment has been made and an information channel acquired, it will be cheaper to keep on using it than to invest in new channels, especially since the scarcity of the individual as an input, already alluded to, implies that the use of new channels will diminish the product of old ones. Thus, it will be difficult to reverse an initial commitment in the direction in which information is gathered."
}

A second reason, rooted in a more competitive perspective, focuses on the opportunity costs of the path not taken rather than on sunk costs: on lock-out as opposed to lock-in. Organizations can be pictured as racing against competitors to build up superior capabilities along particular dimensions and dropping out of a particular race if they fall too far behind. The two different efficiency orientations develop very different sorts of capabilities over time: an emphasis of static efficiency builds functional, economizing 
capabilities while an emphasis of dynamic efficiency builds the capabilities required to change products or processes. To the extent that an emphasis on static efficiency retards efficiency in dynamic terms, or vice versa, a competitor that initially bets on one orientation, and loses, may be deterred from switching to the other by the prospect of being too far behind. Or to paraphrase Arrow ([1974], p. 41), even if the difference between the values of the two possible efficiency orientations and the associated capabilities was initially expected to be small and even if subsequent information suggests that the initial choice between the two was wrong, it may not pay to reverse that decision later on.

A third reason focuses on the people within an organization and emphasizes the difficulty rather than the undesirability of change. The two efficiency orientations would appear to attract rather different sets of employees, making it hard to reverse an initial choice of orientation without replacing many of them. Table 2 illustrates this point by contrasting employee behavioral profiles assembled by Schuler and Jackson [1989]. ${ }^{4}$ The differences are so stark that one might even argue that the two efficiency orientations lead to very different organizational cultures. Such socially complex resources are notoriously difficult to manage systematically (Barney [1991]).

Table 2. Employee behavior profiles

Static-efficient behavioral profile

Relatively repetitive and predictable behavior

Rather short-term focus

Primarily autonomous or individual activity

Low risk-taking activity

High degree of comfort with stability
Dynamic-efficient behavioral profile

High degree of creative behavior

A longer-term focus

High level of cooperative, interdependent behavior

A greater degree of risk-taking

A high tolerance of ambiguity and unpredictability

Source: Adapted from Schuler and Jackson [1989].

A final reason for commitments to particular ways of organizing focuses on the behavioral bases of choice and the inertial tendencies built into them. To begin at the micro level, consider the bases of individual choice depicted in Figure 3. It should be obvious how inactivity and routines tend to induce inertia. Principles, defined here as binding constraints that supersede cost-benefit calculations, will have the same effect to the extent that they are fixed. Finally, psychological experiments suggest that even when choice is calculated, it may be biased in ways that compound the economic sources of commitment discussed above. In particular, the sunk cost fallacy may reinforce lock-in into particular information channels, and the lack of vividness of the path not taken may exacerbate the effects of lock-out from the set of capabilities needed to pursue a different efficiency orientation. Organizational theory also specifies a number of reasons why these micro sources of behavioral commitment might be expected to coalesce into more macro ones. Two that are particularly interesting from the standpoint of learning are defensiveness (Argyris [1990]) and group thinking (Janis and Mann [1977]). 
Figure 3. The behavioral basis of choice

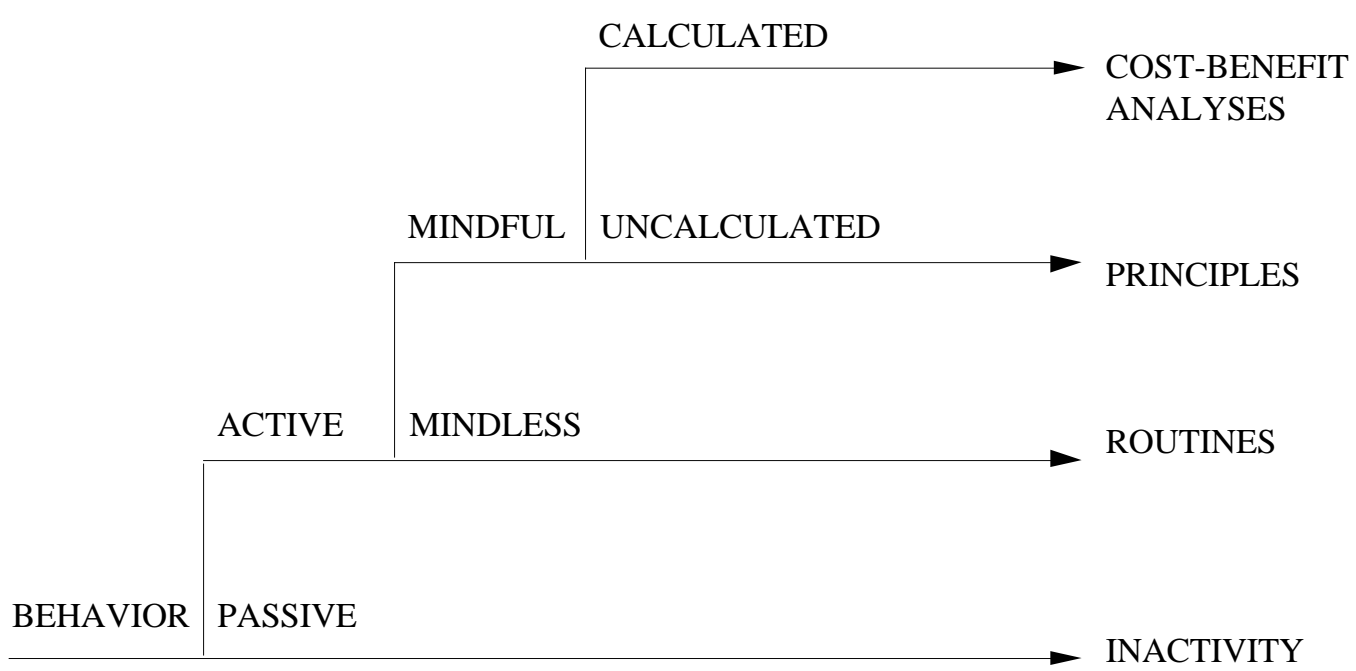

Source: Ghemawat [1991].

For these (overlapping) reasons, we think that it is realistic to assume that the choice of $\mathrm{x}$ is fixed over intervals of significant duration. As demonstrated above, such fixity or commitment increases the amount of attention that should be paid to dynamic efficiency relative to the single-period benchmark. The idea is that when $\mathrm{x}$ itself is fixed, the sort of flexibility afforded by dynamic efficiency becomes more valuable.

\section{Performance hypotheses}

The previous two sections focused on theoretical models. This section turns to empirical matters. While it does not serve up any measurements, it supplies testable hypotheses about systematic influences on the comparative performance of orientations toward static versus dynamic efficiency. The hypotheses highlight the influence of basic industry conditions and strategic choices on the relative profitability of the two efficiency orientations. The discussion is organized in terms of three basic dimensions: industry attributes, business strategy and corporate strategy.

The associations are expected, along each of these dimensions, to be noisy because organizational arrangements are conditioned by historical influences (or what Bartlett and Ghoshal [1989] term administrative heritage) as well as by the incentive effects of environmental contingency and strategic choice. The divergence between actual organizational arrangements and those that would be optimal is likely to be greatest when period-by-period optimization of organizational arrangements is infeasible, i.e., when there are significant precommitments that induce inertia. Some of the micro sources of inertia were discussed at the end of the last section. Numerous macro organizational factors have also been flagged as suspects: size, longevity, maturity, complexity, decentralization, bureaucratization, and (top) management continuity. There seem to be feedback effects from the organization's performance history as well: a history of success or of improving 
performance seems more likely to induce greater inertia. A full-blown treatment of organizational inertia is beyond the scope of this section. It focuses, instead, on how the organization's industry environment(s) and its strategy are likely to influence its incentives to adopt one efficiency orientation as opposed to another. The treatment is, of necessity, tentative.

\subsection{Industry attributes}

The models developed earlier in this paper prove particularly helpful in highlighting the possible influences of industry-level attributes on optimal efficiency orientations. The influences are all moderated by $\lambda$, which represents the sort of environmental uncertainty that Lawrence and Lorsch [1967] emphasized in their classic treatment of the organization's relationship to its environment. We aim to build on their work by proposing more specific criteria that determine whether a particular industry is more likely to emphasize static or dynamic efficiency.

It is useful to begin by reminding ourselves that low values of $\lambda$, or high rates of environmental change, tend to imply low values of $x^{*}$, i.e., an emphasis on dynamic efficiency. Industry attributes that are positively (negatively) correlated with environmental dynamism should therefore tilt organizations toward dynamic (static) efficiency orientations. Several overlapping indicators of industry dynamism can be identified. First, industries that exhibit high investment-intensities are likely to offer participants rich opportunity sets, expanding the scope for dynamism. This appears to be especially true of industries in which investment is weighted toward intangible resources, such as knowledge or relationships, rather than tangible resources such as physical capacity (Collis and Ghemawat [1993]). A second indicator of industry dynamism is the rate at which its key resources depreciate. Other things being equal, industries in which key resources (other than organizational arrangements, which are a sort of meta-resource) are relatively long-lived should imply more emphasis on static efficiency so as to ensure efficient utilization of the assets in place, and those in which key resources have relatively short lives more emphasis on dynamic efficiency. A third indicator of dynamism is the rate at which an industry's real prices, adjusted for changes in quality, are declining. If average real prices are stagnant (or increasing), the emphasis is likely to fall on static efficiency; if they are decreasing by more than a threshold rate ( 2 to 8 percent per year according to Williams [1992]), the emphasis is likely to be on dynamic efficiency.

A second set of industry-level influences on efficiency orientation pertains to changes in $\lambda$ over time, as opposed to its level, which has so far been assumed to be fixed. Tot the extent that industries proceed through life cycles during which $\lambda$ declines monotonically, one should expect to see more attention to dynamic efficiency early on and to static efficiency later (e.g., Abernathy and Utterback [1978]). More recent research reminds us, however, that change need not be monotonic: that $\lambda$ may, for instance, increase sharply after a long period of gradual decline (e.g., Abernathy, Clark and Kantrow [1984]; Baden Fuller and Stopford [1992]). Such "dematuring" shocks are likely to lead to a shift in emphasis, from static efficiency toward dynamic efficiency.

A third set of industry-level influences on efficiency orientation are related to the continuity or discontinuity of change dynamics. Some industries are driven by a relatively continuous dynamic which effectively enhances or at least preserves existing resources or competences; others are driven by a relatively discontinuous dynamic which destroys or 
renders them obsolescent (Tushman and Anderson [1986]). Continuous changes should promote more emphasis on static efficiency whereas discontinuous changes should lead to more of an emphasis on dynamic efficiency if an organization adopts a strategy of trying to compete effectively across discontinuities. But such organization-specific considerations lead us into strategy. The rest of this section considers the implications of an organization's strategic choices for its optimal efficiency orientation.

\subsection{Business Strategy}

While industry-level attributes influence optimal organizational arrangements, they do not determine them up to the point of isomorphism. The reason is that there may be more than one way to outperform the industry averages, implying an independent influence for strategic choices at the business level -he level at which firm-specific and industry-specific effects intersect- on optimal efficiency orientation. In the context of our model, the pursuit of a particular competitive position at the business unit level can be thought of as indirectly influencing $\lambda$ by altering the character of competitive interactions.

One way of relating business strategy and efficiency orientation is in terms of the two "generic" competitive strategies proposed by Porter [1980]: low cost and differentiation. Table 1, which was originally intended to identify differences in the organizational arrangements required to pursue these generic strategies, suggests that the pursuit of a lowcost position goes hand in hand with an emphasis on static efficiency, and the pursuit of a differentiated position with an emphasis on dynamic efficiency. An association between lowcost strategies and the pursuit of static efficiency appears plausible to us, but we find it helpful to unbundle differentiation strategies to distinguish between horizontal differentiation, in which customers' rankings of competing products depend on their tastes, and vertical differentiation, in which customers' rankings coincide (although their willingness to pay for superior products may differ). Strategies that involve vertical differentiation seem to tie in most closely with the pursuit of dynamic efficiency, while strategies that involve horizontal differentiation seem to be more of a mixed bag.

A second way to relate business strategy and efficiency orientation is to compare the attributes of a particular business strategy with the industry-level aggregates discussed in the previous subsection. Since industry aggregates are summed across competing businesses, a significant correlation should be expected between industry-level and business-level attributes. A match between them reinforces the previous subsection's predictions about organizational efficiency imperatives. Divergences can occur as well, however, and can be predicted to have the obvious effects. For example, businesses whose strategies involve relatively high rates of investment, of depreciation of key resources, or of improvements in product performance/cost (the indicators of dynamism discussed in the previous subsection) should be expected to place more emphasis on dynamic efficiency than their median competitors. Their strategies can be thought of as decreasing the $\lambda_{\mathrm{s}}$ that they face relative to the averages for their respective industries.

A third distinction that is of interest is between business strategies that emphasize incremental improvements (e.g., the kaizen strategies popularly associated with Japanese companies) and those that emphasize what, for lack of better terminology, we shall call bigbang changes. While the prospects for these two types of business strategies obviously depend on industry attributes, incremental strategies are likely (other things being equal) to imply more of an emphasis on static efficiency and big-bang strategies on dynamic efficiency. 


\subsection{Corporate strategy}

The discussion in this section has dwelled, so far, on industries and the businesses that compete within them. But economic activity in the most developed countries is dominated by firms that compete in multiple industries. In the United States, for instance, Fortune 500 companies, which account for $40 \%$ of the gross national product, are each active, on average, in 10 discrete lines of business (Collis and Montgomery [1991]). The influence of corporate-level strategic choices on optimal efficiency orientation is also therefore of interest.

It is useful to begin by noting that corporate-level considerations should be superimposed on the predictions from the last two subsections: they do not supplant them. The mere fact that the typical Fortune 500 company operates in 10+ competitive arenas does not mean that it can afford to avoid paying detailed attention to each of them. There are at least four reasons. First, firm-level (i.e., corporate-level) effects on the performance of a constituent business unit appear to be an order of magnitude smaller than effects evident at the industry level or, on a stable basis, at the business unit level (Rumelt [1991]). Second, important firm-specific resources tend to be specialized to particular industries or at least types of industries that share common characteristics, implying that $10+$ industry types can usually be consolidated into a smaller number of industry "clusters" of greater individual importance: in the United States, at least, there is considerable relatedness within the business portfolio of the typical large, diversified corporation (Dosi, Teece and Winter [1990]). Third, even when a corporate portfolio spans industries that are heterogeneous rather than homogeneous, grouping businesses by the types of industries in which they operate may facilitate resource allocation, performance measurement, the optimal design of work processes, et cetera. Finally, if when an organization's key resources are fungible, as in the case of a pure conglomerate or a leveraged buy-out partnership, it will need to consider the possibility of differentiating organizationally across the industries in which it operates in the light of attributes specific to them or to its strategies within them.

The overlay effects of corporate strategy on optimal efficiency orientations can be distinguished in terms of the extent to which the corporate headquarters is involved in strategic planning (Goold and Campbell [1987]). A high level of corporate involvement in strategic planning appears to constrain the extent to which businesses within the corporate portfolio can effectively pursue different efficiency orientations. At the limit, it implies that all businesses within the corporate portfolio must have the same efficiency orientation, making the choice of that orientation a corporate rather than business-level matter. A low level of corporate involvement in planning, in contrast, expands the scope for different efficiency orientations within a multi-business organization, although some impulses toward uniformity continue to be imposed by the need for tight financial controls. ${ }^{5}$ At the limit, when business-level efficiency orientations under the same corporate umbrella are entirely independent of each other, the spotlight shifts away from corporate-level influences on efficiency orientation and back toward influences that operate at the industry and business levels.

\section{Conclusions}

To place this paper in broader perspective, we should point out that the tension between static and dynamic efficiency seems to be central to strategy. To be specific, this tension seems to be an essential element of current debates about the wisdom of pursuing the 
targeted competitive position (static efficiency) versus new visions of how to compete (dynamic efficiency), or pursuing fit with the organization's existing resources, capabilities or strategy versus what Pascale [1991] refers to as transformation and Hamel and Prahalad [1993] as stretch (both neologisms can be associated with dynamic efficiency).

Our analysis of the tension between static and dynamic efficiency demonstrates that there is indeed an extremal logic to what might otherwise be dismissed as rhetorical extremes. It also indicates that to the extent that the pace of change is accelerating ( $\lambda$ is decreasing) or organizational structures are proving more commitment-intensive than we used to think (estimates of $\mathrm{T}$ are increasing), dynamic efficiency deserves more attention that it was previously accorded.

Having said as much, we must close with the reminder that dynamic efficiency is not a generic success factor or panacea. Industry structure and competitive strategy affect the trade-off between static and dynamic efficiency; so, in practice, does the firm's history.

1 If both variances have the same slope in absolute terms, then $\mathrm{z}=1$ and the critical value is $1 / 2$.

2 Several rows of Heskett's original table have been omitted for various reasons, but it has not otherwise been modified.

3 Porter [1980], for instance, recommends generic competitive strategies that involve achieving extreme positions (lower costs or higher prices) and warns firms against getting "stuck in the middle."

4 Schuler and Jackson [1989] actually focus on three distinct competitive strategies: innovation, qualityenhancement and cost-reduction. We have adapted Table 2 from their characterizations of the innovation and cost-reduction strategies. The table omits factors they cite that are hard to translate into our two-way classification.

5 According to Goold and Campbell [1987], a corporation is unlikely to add value to its component businesses if it exerts neither planning nor control influences on them.

\section{References}

Abernathy, William J., The Productivity Dilemma, The Johns Hopkins Press, Baltimore, MD, 1978.

, and James H. Utterback. "Patterns of Innovation in Technology", Technology Review, 80, July 1978, pp. 40-47.

Abernathy, William J., Kim B. Clark, and Alan M. Kantrow, Industrial Renaissance, Basic Books, New York, 1983.

Argyris, Chris, Overcoming Organizational Defenses: Facilitating Organizational Learning, Allyn \& Bacon, 1990. and Donald Schon, Theory in Practice, Jossey-Bass, San Francisco, CA, 1974. 
Arrow, Kenneth J., The Limits of Organization, Norton, New York, 1974.

Ashby, W. Ross, Design for a Brain, John Wiley, New York, 1956.

Baden Fuller, Charles and John M. Stopford, Rejuvenating the Mature Business, Routledge Kegan, London, 1992.

Barney, Jay B. (1991). "Firm Resources and Sustained Competitive Advantage", Journal of Management, 17, 1991, pp. 99-120.

Bartlett, Christopher A. and Sumantra Ghoshal, Managing Across Borders, Harvard Business School Press, Boston, 1989.

Burns, Tom and George M. Stalker, The Management of Innovation, Tavistock Publishing Co., London, 1961.

Carlsson, Bo, "Flexibility and the Theory of the Firm", International Journal of Industrial Organization, 7, 1989, pp. 179-203.

Collis, David J. and Pankaj Ghemawat, "Industry Analysis", forthcoming in Liam Fahey and Robert Randall, eds., The Portable MBA on Strategy, John Wiley, Boston, 1993.

Collis, David J. and Cynthia M. Montgomery (1991). "Corporate Strategy: A Conceptual Framework”, Harvard Business School case \#9-391-284, 1991.

Cyert, Richard M. and James G. March, A Behavioural Theory of the Firm, Prentice-Hall Inc. Englewood Cliffs, NJ, 1963.

Cyert, Richard M. and Morris H. DeGroot, Bayesian Analysis and Uncertainty in Economic Theory, Rowman and Littlefield, Totowa, NJ, 1987.

Dosi, Giovanni, David J. Teece, and Sidney Winter, "Toward a Theory of Corporate Coherence", mimeo, March 1990.

Ghemawat, Pankaj, Commitment: The Dynamic of Strategy, The Free Press, New York, 1991.

Goold, Michael and Andrew Campbell, "Many Best Ways to Make Strategy", Harvard Business Review, no. 6, November-December 1987, pp. 70-76.

Hamel, Gary and C.K. Prahalad, "Strategy as Stretch and Leverage", Harvard Business Review, Vol 71, March-April 1993, pp.75-84.

Hart, Albert G., "Risk, Uncertainty and the Unprofitability of Compounding Probabilities", in Henry Schultz, Oscar Lange, and Francis McIntyre (eds.), Studies in Mathematical Economics and Econometrics, University of Chicago Press, Chicago, IL, 1942, pp. 110-118.

Heskett, James L., "Establishing Strategic Direction: Aligning Elements of Strategy", Harvard Business School Note \#9-388-033, 1987.

Janis, Irving L. and Leon Mann, Decision Making: A Psychological Analysis of Conflict, Choice, and Commitment, The Free Press, New York, 1977. 
Jensen, Michael C. and William H. Meckling, "Specific and General Knowledge and Organization Structure", in Lars Werin and Hans Wijkander (eds.), Contract Economics, Blackwell, 1992.

Jones, Robert A. and Joseph M. Ostroy, "Flexibility and Uncertainty", Review of Economics Studies, 51, no. 1, January 1984, pp. 13-32.

Klein, Burton H., Prices, Wages and Business Cycles: A Dynamic Theory, Pergamon, New York, 1984.

Knight, Frank H., Risk, Uncertainty, and Profit, A.M. Kelly, New York, 1921.

Lawrence, Paul R. and Jay W. Lorsch, Organization and Environment, Richard D. Irwin, Homewood, IL, 1967.

March, James G., and Herbert A. Simon, Organizations, John Wiley, New York, 1958.

March, James G., and J. P. Olsen, Ambiguity and Choice in Organizations, Norway Universitetsforlaget, Bergen, 1976.

Marshack, T. and Richard R. Nelson, "Flexibility, Uncertainty, and Economic Theory", Metroeconomica, XIV, 1962, pp. 42-58.

Miller, Daniel and Peter H. Friesen, Organizations: A Quantum Approach, Prentice-Hall, Englewood Cliffs, NJ, 1984.

Pascale, Richard T., Managing on the Edge, Simon and Schuster, New York, 1991.

Porter, Michael E., Competitive Strategy, The Free Press, New York, 1980.

Rumelt, Richard P., “How Much Does Industry Matter?”, Strategic Management Journal, 12, no. 3, March 1991, pp. 167-185.

Schuler, Randall S. and Susan E. Jackson, "Linking Competitive Strategies with Human Resource Management Practices", reprinted in Arthur A. Thompson, Jr. (ed.), Strategy Formulation and Implementation: The Tasks of General Management, Fourth ed., BPI Irwin, Boston, 1989.

Stigler, George, "Production and Distribution in the Short Run", Journal of Political Economy, 47, June 1939, pp. 305-327.

Tushman, Michael L. and Paul Anderson, “Technological Discontinuities and Organizational Environments", Administrative Science Quarterly, 31, 1986, pp. 439-465.

Williams, Jeffrey R., "How Sustainable Is Your Competitive Advantage?", California Management Review, 34, no. 3, Spring 1992, pp. 29-51.

Woodward, Joan, Industrial Organization: Theory and Practice, Oxford University Press, Cambridge, 1965. 


\section{IESE}

\section{DOCUMENTOS DE INVESTIGACION - RESEARCH PAPERS}

No. TITULO

AUTOR

D/ 236 Innovation: Key elements and characteristics.

Muñoz-Seca B.

October 1992, 21 Pages

D/ 237 Normalidad de las rentabilidades bursátiles.

Octubre 1992, 41 Págs.

Martínez Abascal E.

Arnillas M.L.

D/ 238 Historical returns of stocks, bonds, bills and inflation in the Spanish capital markets.

Sebastian A.

December 1992, 23 Pages

Suárez J.L.

D/ 239 Sobornos y extorsiones en los negocios.

Enero 1993, 17 Págs.

Melé D.

D/ 240 Elementos relevantes para el análisis del sector bancario en los

Noussan G.L. años 90.

Enero 1993, 58 Págs.

D/ 241 A resource - Based view of information systems: A proposal for a

Andreu R. resource based theory of IS and an agenda for research.

March 1993, 38 Pages

D/ 242 Formación, entrenamiento y desarrollo de capacidades y habilidades directivas en las empresas españolas en los primeros noventa.

Marzo 1993, 48 Págs.

D/ 243 Initial public offerings (IPOs): The Spanish experience. March 1993, 20 Pages

Rahnema A.

Fernández $\mathrm{P}$.

Martínez Abascal

D/ 244 Outsourcing in Spain: An empirical study of top management's perspective.

March 1993, 18 Pages

Valor J.

Andreu R.

Fonstad D.

D/ 245 La credibilidad de los códigos éticos.

Abril 1993, 17 Págs.

Argandoña A. 
IESE

\section{DOCUMENTOS DE INVESTIGACION - RESEARCH PAPERS}

No. TITULO

AUTOR

D/ 246 Occasional ethical consultancy.

Argandoña A

April 1993, 13 Pages

Gual J.

D/ 247 La competencia en el mercado español de depósitos bancarios. Abril 1993, 28 Págs.

Argandoña A

D/ 248 Business, law and regulation: Ethical issues

June 1993, 32 Pages

Melé D.

D/ 249 Corporations and the «social contract»: A reply to Prof Thomas Donaldson.

Sison A.

June 1993, 15 Pages

D/ 250 La competitividad sectorial de la industria española.

Junio 1993, 36 Págs.

Gual J.

Hernández A.

D/ 251 ¿Aprovecha sus activos estratégicos?

Junio 1993, 22 Págs.

García Pont C.

Enrione A.

D/ 251 Are you making the most of your strategic assets?

BIS Junio 1993, 17 Pages

García Pont C.

Enrione A.

D/ 252 ¿Se puede mejorar el sistema monetario europeo?

Argandoña A.

Septiembre 1993, 16 Págs.

D/ 253 La política monetaria española: Lecciones para el futuro.

Septiembre 1993, 14 Págs.

Argandoña A.

D/ 254 Managing intemationally: The international dimensions of the managerial task (Abridged version)

Roure J. September 1993, 12 Pages

Alvarez J.L. García Pont C.

Nueno J.L. 